\title{
耳鳴の自覚的評価
}

\author{
児玉 章・北原 正章 \\ 駒田 佳子・平田 晃一
}

\section{Evaluation of Subjective Complaints of Patients with Tinnitus}

\author{
Akira Kodama, Masaaki Kitahara, \\ Keiko Komada and Koichi Hirata \\ (Shiga University of Medical Science)
}

\begin{abstract}
A five-score scale was used to evaluate each of the following three aspects of subjective complaints of patients with tinnitus: 1) loudness, 2) degree of annoyance, and 3) interference with life activities. The tinnitus severity scale was defined as the sum of the scores of these three characteristics. The relationship among these three characteristics was analyzed, and five types of tinnitus were defined from data obtained by the questioning of 346 out-patients. The results were compared with those from 87 in-patients.

(1) The percentages of the types of tinnitus differed between out- and in-patients.

(2) In $74 \%$ of the out-patients the tinnitus severity scale was below 9 and in $76 \%$ of the inpatients it was 9 or more.

(3) Patients whose scores of annoyance and interference with life activities were higher than those of loudness and patients with scores of 9 or more tended to have physical or psychological problems in addition to their tinnitus.
\end{abstract}

Key words: subjective complaint, type of tinnitus, severity scale

\section{はじめに}

治療を要する耳鳴を見いだし，治療法を選択 し,さらに治療効果を判定するためには, 適切 な耳鳴の評価方法が必要であるが，現状では殆 ど確立されてはいない。駒田1)は耳鳴の大きさ， 苦痛度, 仕事・社会生活障害度の 3 項目からな る耳鳴スコアを用いて, そのパターンから耳鳴 を分類し, 各々の型の臨床的特徵を詳細に検討 し，これまで断片的に捉えがちであった耳鳴を， 耳鳴スコアのパターンとして総合的に評価する ことの有用性を報告した. しかし研究の対象が，
入院治療を行った耳鳴症例であったことを考慮 すると，耳鳴患者全体の中の特殊な集団をもと に，耳鳴を分類した可能性も否定はできない。 そこで今回は，外来通院治療を行った耳鳴患者 の耳鳴スコアを検討し, その結果から耳鳴を再 度分類し, 各々の型の耳鳴の臨床的特徵を検討 してみた。 またこの分類に従うと, 駒田 ${ }^{1)}$ が検 討した入院治療を行った耳鳴症例は，ぞの様な 特徵を持つのかも併せて検討したので, その結 果を報告する。 
対象と方法

対象は，平成 3 年 1 月から同年12月までの 1 年間に, 滋賀医科大学耳鼻咽喉科外来を受診し

表 1 耳鳴スコアの問診表

（駒田佳子：1991 1), 北原正章, 他：19862)より一部改変）

耳鳴の大きさ

1。きこえない

2、わずかにさこえる

3 . 中等度

4. 大変つよい

5。不快な程つよい

耳鳴の苦痛度

1. 注意すればあるが，そらわずらわしくない

2. 時にわずらわしい

3. 努力しても無視できない

4. 常にわずらわしく, 時々苦痛だ

5.わずらわしいというより我慢できない

耳鳴の仕事・社会生活障害度

1. 仕事にさしつかえは殆どない

2. 少しはさしつかえるが大丈夫

3. 耳鳴のため仕事するのに相当努力を要する

4. 日常生活がつよく傷害され, 単純作業しか できない

5. 仕事は何もできない
た耳鳴が主訴または主要症状の346例の外来患 者(以下外来症例と略す) と, 激しい耳鳴のため 昭和 61 年 8 月から昭和 63 年 12 月までの期間に入 院治療を行った 87 例の入院患者 (以下入院症例 と略す)である。これらの耳鳴患者の問診の際 に，表 1 に示す耳鳴スコアの問診表を用いて耳

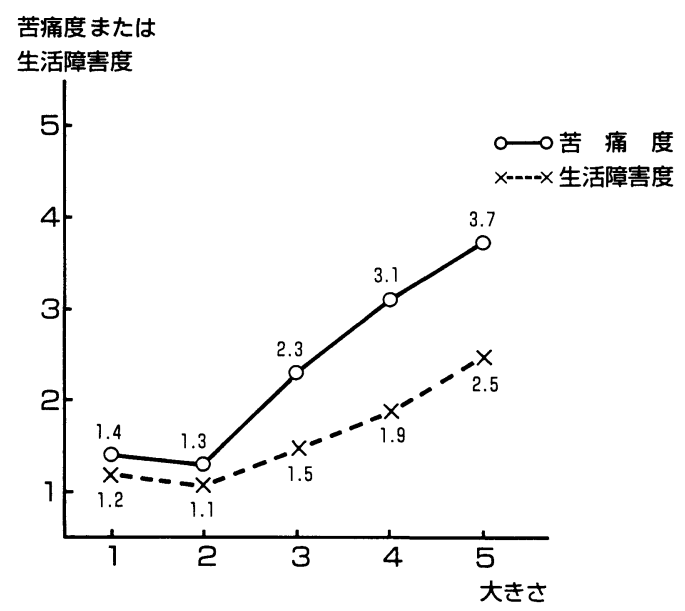

図 1 耳鳴の大きさ別にみた苦痛度, 生活障害度 の平均値

各大きさに対する苦痛度, 生活障害度の平均值を 示寸.
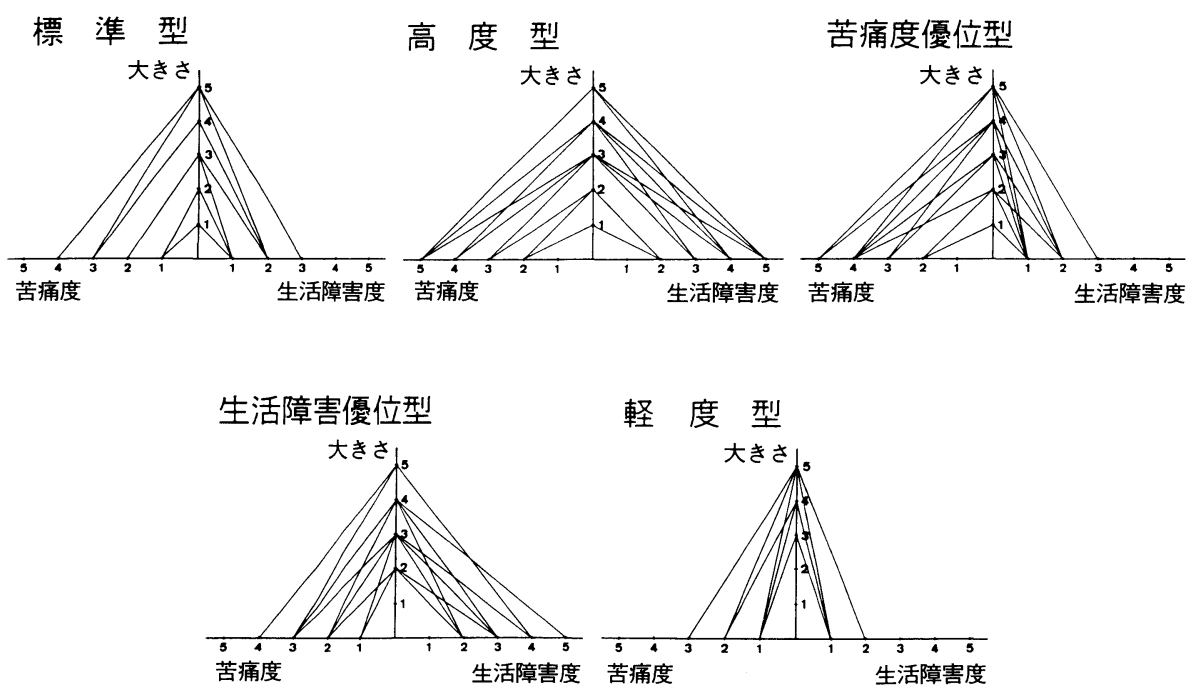

図2耳鳴スコアの分布による耳鳴の 5 つの型

3つの耳鳴スュアの関係から分類した，5つの耳鳴の型を図示する. 
鳴の大きさ, 苦痛度, 仕事・社会生活障害度 (以 下生活障害度と略す)の評価を行った。

方法は, まず外来症例 346 例の, 耳鳴の大き さ $1 \sim 5$ に対する苦痛度と生活障害度のスコア の平均を求め(図 1 ), この平均值から外来症例 を以下の 5 つの型に分類した.

1 ) 標準型

2 ）苦痛度 - 生活障害度高度型(以下高度型)

3 ) 苦痛度優位型

4 ) 生活障害度優位型 (以下生活障害優位型)

5 ) 苦痛度 - 生活障害度軽度型 (以下軽度型)

標準型とは, 大きさに対する苦痛度, 生活障 害度のスコアが平均值に近い症例, 高度型は大 きさに対し苦痛度, 生活障害度の両方が大さい 症例, 苦痛度優位型は大きさに対し苦痛度の程 度のみが高い症例, 生活障害優位型は大きさに 対し生活障害度の程度のみが高い症例, 軽度型 は苦痛度, 生活障害度の両方が低い症例を示す。 図 2 に, 3 つの耳鳴スコアの関係から分類した, 5 つの耳鳴の型を図示する.

次いで，この外来症例をもとにした耳鳴の型 の分類に従らと, 入院症例 87 例の耳鳴スコアは
どの様になるのかを検討してみた，さらに $3 つ$ のスコアの総和を「耳鳴重症度」として 3 点か ら15点で表示し, 併せて検討した. 入院患者に はSDS (self-rating depression scale), CMI (Cornell Medical Index), MAS (manifest anxiety scale)の 3 つの心理テストを行い， らつ状態， 神経症的傾向, 不安の指標とした.

\section{結果}

外来症例の耳鳴スコアの平均値は, 大きさ 3.0 , 苦痛度 2.3 , 生活障害度 1.6 であった. 表 2 に, 外来症例346例の耳鳴の型を分類した内容 と, 症例の割合を示す。標準型が159例 (46\%), 次いで苦痛度優位型が87例 (25\%), 高度型が39 例 (11\%), 軽度型が35例 (10\%), 生活障害優位 型が26例 ( $8 \%$ )であった。

一方, 入院症例の耳鳴スコアの平均値は, 大 きさ3.8, 苦痛度 3.5 , 生活障害度 2.7 であった。 表 3 亿, 外来症例の耳鳴スコアの分類に従い, 入院症例87例の耳鳴を分類した内容と, 症例の 割合を示す.耳鳴の大きさに対し苦痛度, 生活 障害度ともに高い高度型が28例 (32\%) と最多で, 生活障害優位型は 20 例 (23\%), 苦痛度優位型と

表 2 各型の耳鳴スコアの内容と症例の割合 (外来症例)

\begin{tabular}{|c|c|c|c|c|c|}
\hline 耳鳴の型 & 標準型 & 高度型 & $\begin{array}{l}\text { 苦痛度 } \\
\text { 優位型 }\end{array}$ & $\begin{array}{l}\text { 生活障害 } \\
\text { 優位型 }\end{array}$ & 軽度型 \\
\hline \multirow{14}{*}{$\begin{array}{l}\text { 耳鳴スコア } \\
\text { の内容 }\end{array}$} & 111 & 122 & 121 & 212 & $\begin{array}{lll}3 & 1 & 1\end{array}$ \\
\hline & 211 & 222 & 221 & 312 & 411 \\
\hline & 321 & 232 & 241 & 323 & 421 \\
\hline & 322 & 333 & 331 & 324 & 511 \\
\hline & 432 & 343 & 332 & 422 & 521 \\
\hline & 533 & 344 & 341 & 433 & 522 \\
\hline & 542 & 345 & 342 & 435 & 531 \\
\hline & 543 & 354 & 431 & 534 & \\
\hline & & 443 & 441 & 544 & \\
\hline & & 454 & 442 & & \\
\hline & & 455 & 451 & & \\
\hline & & 554 & 541 & & \\
\hline & & 555 & 552 & & \\
\hline & & & 553 & & \\
\hline 症例数 (\%) & $159(46)$ & $39(11)$ & $87(25)$ & $26(8)$ & $35(10)$ \\
\hline
\end{tabular}

※耳鳴スコアの内容は左より大きさ, 苦痛度, 生活障害度を示す. 
標準型がそれぞれ 18 例 (21\%)で，軽度型は 3 例 (3\%)であった。

図 3 K, 外来症例と入院症例の $5 つ$ 鵈の 型の割合を示す. 外来症例に比べると入院症例 では, 標準型と軽度型の症例の割合が減少し, 高度型と生活障害優位型の割合が高くなってい た。

大きさ, 苦痛度, 生活障害度の 3 つのスコア の総和である「耳鳴重症度」と, 耳鳴の型との 関係を，外来症例で検討した結果を表 4 に示す。 外来症例の中で 255 例 $(74 \%)$ は, 耳鳴重症度 8 以下であった。
入院症例の耳鳴重症度と耳鳴の型の関係を表 5 亿示す. 外来症例に比べると耳鳴重症度の高 い症例が多く, 入院症例の中で66例 (76\%) は, 耳鳴重症度 9 以上であった。

表 6 に，心理検査を施行できた入院症例の結 果から得た，耳鳴の型による特徵を示す。 SDS 48点以上のうつ状態にある症例の割合は, 高度型, 苦痛度優位型で高く, 標準型, 生活障 害優位型, 軽度型では僅かであった. 神経症的 傾向を示す CMI や不安の指標の MAS では特 に差を認めなかった。 頭痛, 頭重感, 肩凝り, 不眠等の不定愁訴を訴えた症例の割合は，苦痛

表 3 各型の耳鳴スコアの内容と症例の割合（入院症例）

\begin{tabular}{|c|c|c|c|c|c|}
\hline 耳鳴の型 & 標準型 & 高度型 & $\begin{array}{l}\text { 苦痛度 } \\
\text { 優位型 }\end{array}$ & $\begin{array}{l}\text { 生活障害 } \\
\text { 優位型 }\end{array}$ & 軽度型 \\
\hline \multirow{10}{*}{$\begin{array}{l}\text { 耳鳴スコア } \\
\text { の内容 }\end{array}$} & 321 & 222 & 242 & 223 & 311 \\
\hline & 322 & 233 & 342 & 312 & 421 \\
\hline & 432 & 343 & 431 & 323 & \\
\hline & 542 & 344 & 441 & 334 & \\
\hline & 543 & 354 & 442 & 422 & \\
\hline & & 443 & 541 & 433 & \\
\hline & & 445 & 552 & 444 & \\
\hline & & 454 & & 534 & \\
\hline & & 554 & & 544 & \\
\hline & & 555 & & & \\
\hline 症例数 $(\%)$ & $18(21)$ & $28(32)$ & $18(21)$ & $20(23)$ & $3(3)$ \\
\hline
\end{tabular}

※耳鳴スコアの内容は左より大きさ, 苦痛度, 生活障害度を示す.
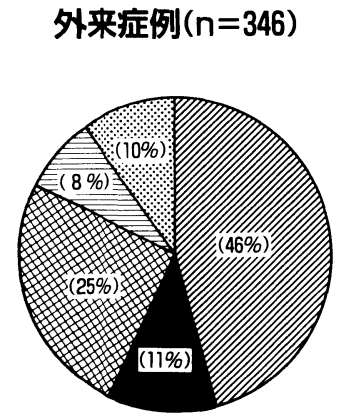

入院症例 $(n=87)$

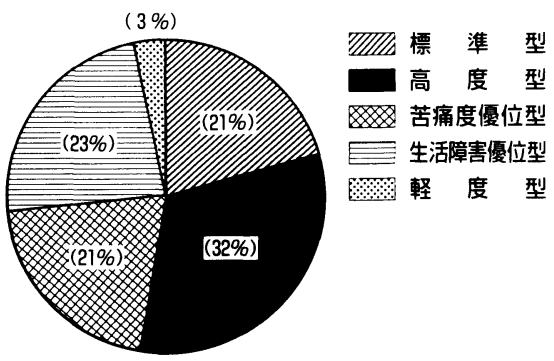

図 3 耳鳴の型の割合

耳鳴の型の割合を外来症例と入院症例とで比較して示す，入院症例で は標準型や軽度型が少なく, 高度型や生活障害優位型の割合が多い。 
度優位型, 生活障害優位型, 高度型でやや高か った。

表 7 に，心理検査を施行できた入院症例の結 果から得た，耳鳴重症度の特徵を示す．5つ状 態，神経症的傾向，不安，不定愁訴を訴学る症 例ともに耳鳴重症度 $9 \sim 15$ の症例で割合が高く なっていた。

\section{考案}

耳鳴は本来主観的な感覚であるため，耳鳴を 評価する上では患者自身による大ささや気にな り方の表現が最も重要である3゙，この様な耳 鳴の評価方法は現状では確立されて抢らず，従 ってその有用性が検討されることも少なかっ た1).今回用いた耳鳴スコアは，オレゴン大学

表 4 耳鳴重症度と耳鳴の型(外来症例)

\begin{tabular}{|c|c|c|c|c|c|c|}
\hline 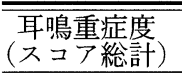 & 標準型 & 高度型 & $\begin{array}{l}\text { 苦痛度 } \\
\text { 型 }\end{array}$ & $\begin{array}{l}\text { 生活障害 } \\
\text { 優位型 }\end{array}$ & 軽度型 & $\begin{array}{c}\text { 症例数 } \\
(\%)\end{array}$ \\
\hline 3 & 9 & & & & & \\
\hline 4 & 50 & & 3 & & & \\
\hline 5 & & 3 & 19 & 4 & 16 & 255 \\
\hline 6 & 59 & 1 & & 5 & 3 & (74) \\
\hline 7 & 26 & 3 & 12 & & 10 & \\
\hline 8 & & & 24 & 7 & 1 & \\
\hline 9 & 6 & 7 & 12 & 1 & 5 & \\
\hline 10 & & 6 & 13 & 5 & & \\
\hline 11 & 5 & 11 & & & & 91 \\
\hline 12 & 4 & 2 & 1 & 2 & & (26) \\
\hline 13 & & 1 & 3 & 2 & & \\
\hline 14 & & 4 & & & & \\
\hline 15 & & 1 & & & & \\
\hline 症例数 $(\%)$ & $159(46)$ & $39(11)$ & $87(25)$ & $26(8)$ & $35(10)$ & 346( \\
\hline
\end{tabular}

表 5 耳鳴重症度と耳鳴の型(入院症例)

\begin{tabular}{|c|c|c|c|c|c|c|}
\hline 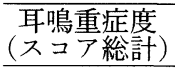 & 標準型 & 高度型 & $\begin{array}{l}\text { 苦痛度 } \\
\text { 優位型 } \\
\end{array}$ & $\begin{array}{l}\text { 生活障害 } \\
\text { 優位型 }\end{array}$ & 軽度型 & $\begin{array}{c}\text { 症例数 } \\
(\%)\end{array}$ \\
\hline \multicolumn{7}{|l|}{3} \\
\hline \multicolumn{7}{|l|}{4} \\
\hline 5 & & & & & 1 & 21 \\
\hline 6 & 3 & 1 & & 1 & & (24) \\
\hline 7 & 7 & & & 1 & 2 & \\
\hline 8 & & & 3 & 2 & & \\
\hline 9 & 5 & & 6 & & & \\
\hline 10 & & 3 & 8 & 4 & & \\
\hline 11 & 2 & 15 & & & & 66 \\
\hline 12 & 1 & 1 & 1 & 8 & & (76) \\
\hline 13 & & 2 & & 4 & & \\
\hline 14 & & 4 & & & & \\
\hline 15 & & 2 & & & & \\
\hline 症例数（\%) & $18(21)$ & $28(32)$ & $18(21$ & $20(23)$ & $3(3)$ & $87(10$ \\
\hline
\end{tabular}


表 6 耳鳴の型による特徵

\begin{tabular}{|c|c|c|c|c|c|}
\hline 項 目 & 標準型 & 高度型 & $\begin{array}{l}\text { 苦痛度 } \\
\text { 優位型 } \\
\end{array}$ & $\begin{array}{l}\text { 生活障害 } \\
\text { 優位型 }\end{array}$ & 軽度型 \\
\hline SDS 48点以上 & $1(6)$ & $12(43)$ & $7(39)$ & $4(20)$ & 0 \\
\hline SDS 平均点 & [37.1] & {$[45.6]$} & {$[43.4]$} & [41.9] & {$[39.5]$} \\
\hline CMI III N & $9(50)$ & $14(50)$ & $6(33)$ & $7(35)$ & $1(33)$ \\
\hline MAS I & $6(33)$ & $8(29)$ & $5(28)$ & $5(25)$ & 0 \\
\hline 不定愁訴あり & $8(44)$ & $18(64)$ & $13(72)$ & $13(65)$ & $2(67)$ \\
\hline 症例数 & 18 & 28 & 18 & 20 & 3 \\
\hline
\end{tabular}

の耳鳴クリニックで考案された Tinnitus clinic questionnaire $^{4)}$ の一部を日本語訳したもの ${ }^{122)}$ であり, 単に耳鳴の大ささと苦痛度だけを評価 するのではなく, 大ささと苦痛度・生活障害度 とを分けて検討した点が特徵である. 駒田 ${ }^{11}$ は この耳鳴スコアを用いて，入院治療を行った87 例の耳鳴患者を詳細に検討し，耳鳴スコアのパ ターンとして総合的に評価することの有用性を 報告した。 しかし，対象が入院治療を行った耳 鳴症例であったため，耳鳴患者全体の中からみ ると，特殊な集団を検討した可能性もあった。 そこで今回は，なるべく一般的で，しかもでき るだけ多数の耳鳴症例を対象として, 耳鳴スコ アの相互関係から耳鳴を分類し, 臨床的特徵を 検討してみた。

まず，外来症例346例の耳鳴スコアの成績を もとに, 耳鳴のスコアのパターンから耳鳴の型 を 5 つに分類し，さらにこの分類に従って先の 入院症例 87 例の耳鳴を再度検討してみた。その 結果, 外来症例と入院症例とでは耳鳴の型の割 合が大きく異なり，入院症例では耳鳴の大きさ に比して苦痛度や生活障害度のスコアの大きい 高度型, 生活障害優位型が多いことが明らかに なった。 また耳鳴スコアの平均値は, 大きさ, 苦痛度, 生活障害度ともに, 入院症例では外来 症例に比べると扣よそ1 ランクずつ高く, 従っ て 3 つのスコア值の合計を耳鳴重症度として検 討すると, 外来症例の扣よそ 4 分の 3 は重症度 8 以下, 入院症例の拈上そ 4 分の 3 は重症度 9
表 7 耳鳴重症度の特徵

\begin{tabular}{l|cc}
\hline 耳鳴重症度 & $3 \sim 8$ & $9 \sim 15$ \\
\hline 項 目 & $2(10)$ & $21(32)$ \\
SDS 48点以上 & {$[38.1]$} & {$[43.7]$} \\
SDS 平均点 & $6(29)$ & $31(47)$ \\
CMI III N & $4(19)$ & $20(30)$ \\
MAS I & $9(43)$ & $46(70)$ \\
不定愁訴あり & 21 & 66 \\
\hline 症例数 &
\end{tabular}

以上と逆の関係にあることも判明した。

また心理検査を行った入院症例の成績から， 耳鳴の大きさに比して苦痛度や生活障害度の高 い症例, 耳鳴重症度 9 以上の症例では，らつ傾 向や不定愁訴を認める症例が多いことが解った。 これららつ傾向や不定愁訴を認める症例は, 複 雑を極める耳鳴臨床を取扱ら上で最も注意を要 する症例であり，耳鳴を単に大きさの評価だけ で捉えていたのでは検出できなかった点である. 従って, 耳鳴の評価の際には大きさの他に苦痛 度, 生活障害度を加光, 総合的に評価すること は意義深く, 耳鳴のスコア, 耳鳴の型, 耳鳴重 症度による判定は, 耳鳴患者の臨床像の把握や, 取扱いに役立つと考えた。

\section{まとめ}

耳鳴の評価を大きさ, 苦痛度, 生活障害度の 3 つの耳鳴スコアにより行った．外来症例の検 討をもとに耳鳴を 5 つの型に分類し，これに従 
い入院症例を再検討した．その結果，入院症例 と外来症例とでは，型の割合が大きく異なって

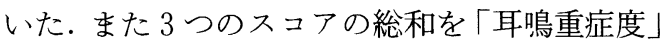
として検討した結果，外来症例の74\%は耳鳴重 症度 8 以下, 入院症例の $76 \%$ は耳鳴重症度 9 以 上であった. 苦痛度や生活障害度の耳鳴スコア の高い症例, 耳鳴重症度 9 以上の症例では, つ傾向や不定愁訴を認める症例が多かった。耳 鳴スコアを総合的に用いての耳鳴の型による分 類や重症度による判定が，耳鳴患者の臨床像の 把握や，取扱いに役立つことを述べた。

尚, 本論文の要旨は平成 4 年 5 月, 第93回日本耳 鼻咽喉科学会総会(名古屋市)で口演した。

\section{参考文献}

1）駒田佳子：耳鳴の評価に関寸る臨床的研究. 耳 鼻臨床 補49: 1 29, 1991.

2) 北原正章, 北嶋和智, 竹田泰三 : 耳鳴研究を進 めるにあたって.耳鼻臨床 79 : 515～523, 1986.

3) Coles RRA, Baskill JL and Sheldrake JB : Measurement and management of tinnitus. J Laryngol Otol 98 : 1171 1176, 1984.

4) Vernon J : Assessment of the tinnitus patient. Tinnitus (ed by Hazell JWP). pp 71 95, Churchill Livingstone, Edingurgh, London, Melbourne and New York, 1987.

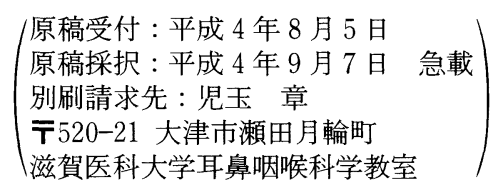

